\title{
Economic Growth with Foreign Capital
}

\author{
Henry Thompson*
}

\begin{abstract}
In growth theory, foreign investment places a small open economy in the international steady state. In applied growth theory, foreign investment is assumed to shift technology. The present growth model separates foreign from domestic capital and develops the steady state where both capital/labor ratios are stationary. A capital scarce country would attract foreign investment and may arrive at a steady state with perpetual foreign investment. Such a steady state foreign investment host is characterized by low saving and high labor growth rates, and source countries the opposite. Incomplete convergence characterizes economic growth with foreign capital.
\end{abstract}

\section{Introduction}

Growth theory assumes that a small economy open to foreign investment is in the international steady state, and the applied growth literature assumes foreign investment shifts technology. In contrast to both, the present model separates foreign from domestic capital with the steady state where the two capital/labor ratios become stationary. Incomplete convergence characterizes this growth model with foreign capital. With relatively low saving and high labor growth rates, a small open economy would be a steady state foreign investment host with a perpetual capital account surplus. The implication is a steady state current account deficit with the domestic capital return remaining above and wage below their international levels. In the two country model there is incomplete convergence.

\section{Domestic and Foreign Investment and Technology}

Introduce Hicks neutral technology into the Solow (1956) and Swan (1956) constant returns neoclassical production function $y(k, t)$ where $y$ is per capita (worker) output, $k$ is the capital/labor ratio $K / L$, and $t$ represents technology. Letting dots ${ }^{\bullet}$ represent time derivatives, $y^{\bullet} \equiv \mathrm{d} y / \mathrm{d} t=y_{k} k^{\bullet}+y_{t} t^{\bullet}$. Competitive input markets imply input prices equal marginal products, $r=y_{k}$ and $w=y-y_{k} k$, where $r$ is the capital return and $w$ the wage.

The applied growth literature assumes foreign investment improves technology focusing on the technology shift term $y_{t} t^{*}$. Examples include Barro and Sala-i-Martin (1999), Blomström et al. (1992), De Gregorio (1992), Berthelemey and Demurger (2000), and Bengoa and Sánchez-Robles (2003). Separating technology from capital is tenuous even at the disaggregated industrial level in applied production analysis since capital inputs and returns have to be estimated and capital shares are typically residuals in production data. Improved technology in practice is taken to be the residual of a

\footnotetext{
* Thompson: Economics, 302 Comer Hall, Auburn University, AL 36849, USA. Tel: 334-844-2910; Fax: 334-844-5639; E-mail: thomph1@auburn.edu. The author would be like to thank John Francis, Valentina Hartarska, Justin Isaacs, Yali Li, Evan Moore, Farhad Rassekh, Greg Traxler, Joe Willis, and Paul Pecorino for useful comments. Special thanks for suggestions leading to the present formulation go to Walt Enders and a referee of this journal.
} 
production or cost regression. While foreign investment may bring local technology up to the international level, it certainly raises the capital stock through the $y_{k} k^{\bullet}$ effect. The lack of consensus on the effect of foreign investment is exemplified by Aitken et al. (1996) finding positive technology spillovers from foreign ownership while Aitken and Harrison (1999) do not.

In the present model, foreign investment augments the domestic capital stock but does not change technology. If $t^{\bullet}=0$ it follows that $y^{\bullet}=y_{k} k^{\bullet}$, where $k^{\bullet}=K^{\bullet} / L-\lambda k$ and $\lambda \equiv L^{\bullet} / L$, the constant growth rate of labor. In a host country, total capital $K$ is domestic plus foreign capital and $K^{\cdot}=K_{D}^{\cdot}+K_{F}^{\cdot}$. If $K_{F}^{\cdot}>0$, foreign investment is added to the capital stock along with domestic saving. The present paper focuses on a capital scarce foreign investment host country but analysis is symmetric for a source country with some domestic saving going abroad.

A capital scarce country would have a lower autarky capital/labor ratio $k$ than the international $k^{*}$ and a higher capital return $r$ than the international $r^{*}$. The theoretical growth literature does not separate foreign from domestic capital and the economy moves to the international steady state, where $k=k^{*}$ and $r=y_{k}\left(k^{*}\right)=r^{*}$. The present model separates foreign from domestic capital with the growth of each capital/labor ratio reaching zero in the steady state.

The literature includes models with a distinction between domestic and foreign capital. Mussa (1982) introduces imperfect substitution between domestic and foreign capital. International capital returns would differ in the steady state due to the local productive factors of Leamer (1980), international risk differences of Grossman and Shapiro (1982), and externalities due to capital/labor ratio differences of Lucas (1990). Separating foreign from domestic capital is also suggested by information asymmetries, local discrimination, and required local sponsorship.

\section{Imperfect Foreign Investment}

Domestic capital $K_{D}$ grows with saving and depreciates at the constant rate $\delta$,

$$
K_{D}^{\cdot}=\sigma Y_{D}-\delta K_{D}
$$

where domestic income $Y_{D}$ in the host country is output $Y$ less interest payments on foreign capital, $Y_{D} \equiv Y-r K_{F}$. The following discussion focuses on a host country but analysis of a source country is symmetric with foreign interest payments $r^{*} K_{H}$ on home-owned capital abroad added to domestic income.

It would be straightforward to extend the present model to include optimal saving in an overlapping generation model with maximized homothetic utility over two lifetime periods along the lines of Ramsey (1928), Cass (1965), and Koopmans (1965). With homothetic time preferences the saving rate would be invariant with respect to income and there would be an unambiguous positive substitution effect of a fall in $r$ implying a negative first-order saving effect. For simplicity, the present model assumes an exogenous saving rate but present results are consistent with a negative first-order effect.

Foreign investment is assumed to be a partial adjustment function of the discounted difference between international and domestic capital/labor ratios, $\Phi\left(\alpha k^{*}-k\right)$, where $0<\Phi, \alpha \leq 1$. The international capital/labor ratio $k^{*}$ is exogenous for a small open economy. The adjustment parameter $\Phi$ controls the speed of adjustment and the discount parameter $\alpha$ governs how close the host country would get to the international level.

The foreign capital stock in the host country changes according to 


$$
K_{F}^{\cdot}=\Phi\left(\alpha k^{*}-k\right)-\delta K_{F}
$$

An equivalent but less transparent specification is $\Phi\left(r-\beta r^{*}\right)$, where $0<\beta \leq 1$. Adjustment in the stock of home capital abroad for a host country is $K_{H}^{\bullet_{H}}=\Phi\left(k-\alpha k^{*}\right)-\delta K_{H}$. Domestic capital and foreign capital are perfect substitutes and both depreciate at rate $\delta$.

Foreign capital eliminates the curious "start up" problem of neoclassical growth theory due to the Inada condition since an island of stranded workers would attract foreign capital. Growth in a host implies a rising capital/labor ratio but a small open economy may reach its steady state short of $\alpha k^{*}$.

There is perfect foreign investment when $\Phi=\alpha=1$. Imperfect foreign investment adds to the potential applications of the model. Transaction or transport costs of Leamer (1980), Neary (1978), Feenstra and Lewis (1994), and Hamermesh (1989) motivate imperfect capital mobility. Other sources of imperfections include differences in legal system, property rights, business practices, infrastructure, and financial institutions.

Transforming (1) and (2) into per capita (worker) terms, domestic and foreign capital/labor ratios in a host evolve according to

$$
k_{D}^{\cdot}=\sigma\left(y-r k_{F}\right)-\theta k_{D}
$$

and

$$
k_{F}^{\cdot}=\varphi\left(\alpha k^{*}-k\right)-\theta k_{F},
$$

where $\varphi \equiv \Phi / L$ is the per capita foreign investment parameter $0<\varphi<1 / L$ and $\theta \equiv \lambda+\delta$. These first-order differential phase equations add foreign investment and repatriation to the familiar neoclassical phase diagram.

The steady state condition is $k_{D}^{\bullet}=k_{F}^{\bullet}=0$ making (3) a system of two equations in the steady state levels $k_{D}^{s}$ and $k_{F}^{s}$ that sum to $k^{s}$. Solving the system in (3),

$$
k_{D}^{s}=\sigma\left[(\varphi+\theta) y^{s}-\varphi \alpha k^{*} r^{s}\right] / \Delta
$$

and

$$
k_{F}^{s}=\varphi\left(\theta \alpha k^{*}-\sigma y^{s}\right) / \Delta,
$$

where $\Delta \equiv \theta(\varphi+\theta)-\varphi \sigma r^{s}$. The determinant $\Delta$ is positive if $r^{s}<\theta(\varphi+\theta) / \varphi \sigma$, implying parameter restrictions for a sensible economic solution. If $\varphi=1, \lambda=\delta=0.02$ and $\sigma=0.2, \Delta>0$ if $r^{s}<0.208$. With the production function $y=k^{4}$ the equivalent condition is $k^{s}>2.97$. The following analysis assumes $\Delta>0$.

The total capital/labor ratio in the steady state from (4) is

$$
k^{s}=k_{D}^{s}+k_{F}^{s}=\left[\theta \sigma y^{s}+\left(\theta-\sigma r^{s}\right) \varphi \alpha k^{*}\right] / \Delta .
$$

Positive $k_{D}{ }^{s}$ requires $y^{s}>\varphi \alpha k^{*} r^{s} /(\varphi+\theta)$. If in addition to the above assumptions $\alpha=1$ and $k^{*}=10, k_{D}^{s}>0$ if $k^{s}>3.76$. The condition for a steady state host is that $k_{F}^{s}>0$ or $\sigma y^{s}<\theta \alpha k^{*}$ with insufficient saving to cover erosion of the international capital/labor ratio. In the example, $k_{F}^{s}>0$ if $y^{s}<2$ or equivalently $k^{s}<5.66$.

The evolution of foreign investment and capital can be followed in Figure 1. Per capita output $y(k)$ is an increasing concave function and $y_{k}=r$. The $r k_{F}$ term in $k_{D}{ }_{D}$ in (3) evolves according to $\mathrm{d}\left(r k_{F}\right) / \mathrm{d} k=y_{k k} k_{F}-\varphi y_{k}<0$, making $\sigma y_{D}$ concave in $k$ given $y_{k k}<0$. When $k<k_{f}$ in Figure $1, k_{F}$ increases and $\varphi\left(\alpha k^{*}-k\right)>\theta k_{F}$. At $k_{f}$ the stock of foreign 


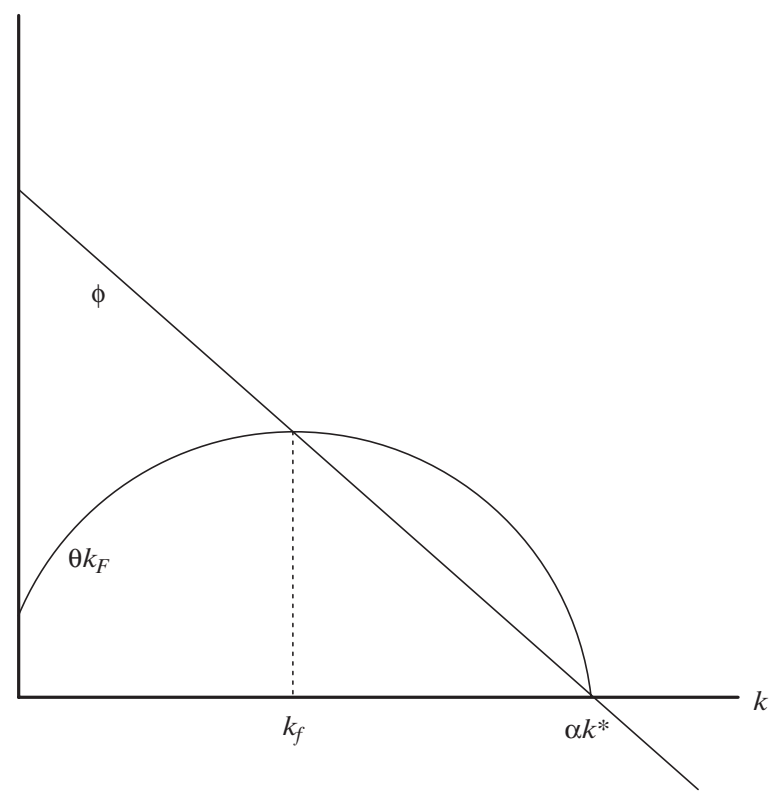

Figure 1. Foreign Investment and Capital

capital $k_{F}$ is maximized and $\varphi\left(\alpha k^{*}-k_{f}\right)=\theta k_{F}$. Beyond $k_{f}$ there is net foreign capital erosion and $k_{F}^{\bullet}<0$. Foreign investment would cease where $k=\alpha k^{*}$ and $k_{F}$ erodes to zero.

The closed neoclassical growth model is stable with a concave phase curve $k^{\bullet}=\sigma-\theta k$ with $\mathrm{d} k^{\bullet} / \mathrm{d} k=\sigma y_{k}-\theta$ and $\mathrm{d}^{2} k^{\bullet} / \mathrm{d} k^{2}=\sigma y_{k k}<0$. In the present model there would be monotonic convergence toward this autarky steady state at $k^{a}=\sigma / \theta$. The slope of the open economy phase line is $\mathrm{d} k^{\bullet} / \mathrm{d} k=\sigma\left(y_{k}-k_{F} y_{k k}-\varphi-\theta\right)$ and the negative second derivative is $\mathrm{d}^{2} k^{\bullet} / \mathrm{d} k^{2}=\sigma y_{k k}$ assuming $y_{k k k}=0$. A capital-poor country would converge monotonically toward $k^{s}$ in (5) falling short of $\alpha k^{*}$ in Figure 1 given the following parametric conditions for a steady state host.

\section{Host and Source Countries}

The steady state condition $k^{s}$ in (5) can be written

$$
\theta \sigma y-\varphi\left(\alpha k^{*}-k\right) \sigma r=\theta\left((\varphi+\theta) k-\varphi \alpha k^{*}\right) .
$$

The per capita saving function $\sigma y$ is an increasing concave function in $k$ and the discounted $\theta \sigma y$ curve of a steady state host country is shown in Figure 2. The other curve in Figure 2 shows the left-hand side of (6) and the two curves intersect where $\alpha k^{*}=k$. From the right-hand side of (6) the ray $\theta(\varphi+\theta) k$ originating at the origin results in the line in Figure 2. The steady state occurs where these two schedules in (6) intersect at $k^{s}$.

A host country beginning in autarky at $k^{a}<k^{s}$ would converge to $k^{s}$ with foreign investment equal to the distance between the two curves in Figure 2. In the steady state $k^{a}<k^{s}<\alpha k^{*}$, implying $r^{a}>r^{s}>r^{*}$ while $w^{a}<w^{s}<w^{*}$ and $y^{a}<y^{s}<y^{*}$.

The steady state current account equals the trade balance $B^{s}$ less net interest payments $r^{s} k_{F}^{s}$. The positive capital account $\varphi^{s} \equiv \varphi\left(\alpha k^{*}-k^{s}\right)$ for the host implies a negative 


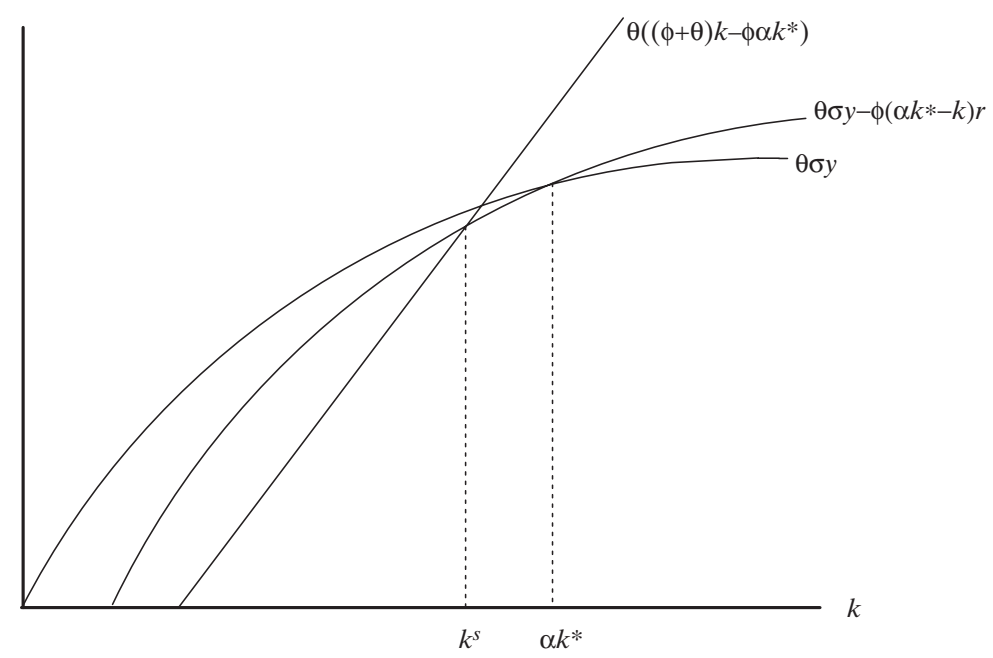

Figure 2. Foreign Investment Host

current account $C^{s}=B^{s}-r^{s} k_{F}^{s}$, although there could be a trade surplus $B^{s}>0$ offset by net interest payments. As $K_{F}$ accumulates, net interest payments $-r K_{F}$ would reach a minimum symmetric to the $\theta k_{F}$ schedule in Figure 1.

In a steady state source country, the equilibrium in (6) would occur at $k^{s}>\alpha k^{*}$ implying a steady state foreign investment outflow. A lower $\theta$, for instance, could result in a flatter right-hand line intersecting the left-hand curve in (6) to the right of $\alpha k^{*}$. For a source country there is a perpetual capital account deficit and current account surplus although a trade deficit is possible. Workers in a source country are better off in autarky but capital owners are worse off, and per capita income falls with a move from autarky to open international investment.

A country is more likely a host if it has higher labor growth $\lambda$, higher depreciation $\delta$, a lower saving rate $\sigma$, or a lower foreign investment parameter $\varphi$. An increase in saving propensity $\varsigma$ would raise the saving schedule, increasing $k^{s}$ and reducing foreign investment making the economy less of a host as $r^{s}$ falls and $w^{s}$ rises. An increase in the foreign capital/labor ratio $k^{*}$ raises foreign investment making a small economy more of a host or less of a source with $k^{s}, w^{s}$, and the capital account rising while $r^{s}$ and the current account fall.

The ratio of foreign to domestic capital $\kappa \equiv k_{F} / k_{D}$ rises if it is less than $\varphi\left(\alpha k^{*}-k\right) /$ $\sigma y_{D}$. If a potential host country starts in autarky at $k^{a}$, where $k_{F}=\kappa=0$, the ratio $\varphi\left(\alpha k^{*}-k\right) / \sigma y$ falls with foreign investment and $\kappa$ converges to its steady state $\varphi\left(\alpha k^{*}-\right.$ $\left.k^{s}\right) / \sigma y^{s}$, where $y^{s}=\sigma y_{D} s+\varphi^{s}$. For a source country the share of home capital going abroad is $\varphi\left(k^{s}-\alpha k^{*}\right) / \sigma y_{D} s$.

\section{The Two Country Model}

Consider the two country model with north $N$ the source country and south $S$ the host. Suppose in autarky $N$ has a higher steady state capital/labor ratio $k_{N}>k_{S}$ implying $r_{S}>r_{N}$ and $w_{N}>w_{S}$. The steady state depends on parameters in the two countries. Where $k_{F}$ represents $N$-owned capital in $S$, the steady state requires $k_{F}^{{ }^{*}}=0$ as well as $k^{\bullet}{ }_{N}=k^{\bullet}=0$. Similar to (3) 


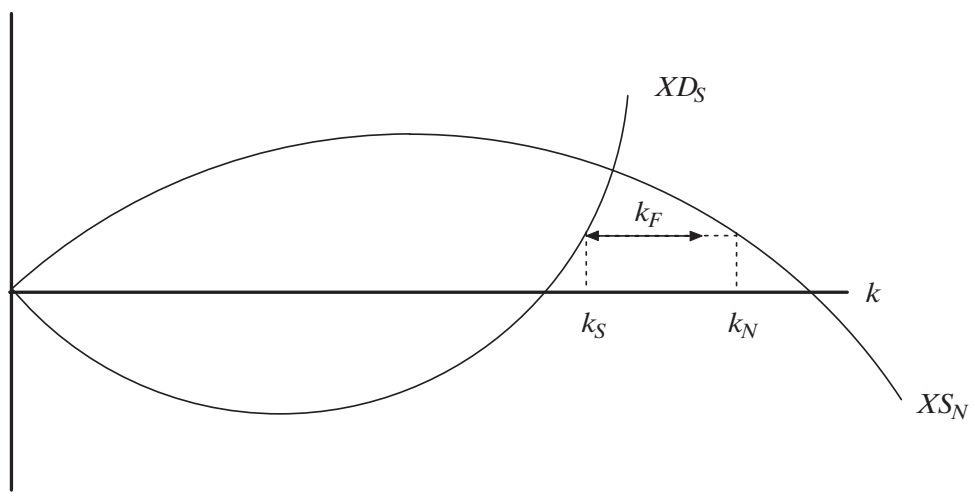

Figure 3. Two Country Model

$$
\begin{aligned}
& k_{N}^{\cdot}=\sigma_{N}\left(y_{N}+r_{S} k_{F}\right)-\left(k_{N}-k_{S}\right)-\theta_{N} k_{N}=0 \\
& k_{S}^{\cdot}=\sigma_{S}\left(y_{S}-r_{S} k_{F}\right)+\left(k_{N}-k_{S}\right)-\theta_{S} k_{S}=0 \\
& k_{F}^{\cdot}=\left(k_{N}-k_{S}\right)-\theta_{S} k_{F}=0,
\end{aligned}
$$

where for simplicity $\varphi=\alpha=1$ with perfect capital mobility.

The excess supply of investment from $N$ must match excess demand in $S$, $k_{N}-k_{S}=\sigma_{N}\left(y_{N}+r_{S} k_{N}^{S}\right)-\theta_{N} k_{N}=\theta_{S} k_{S}-\sigma_{S}\left(y_{S}-r_{S} k_{F}\right)$ from (7). The North excess supply curve $X S_{N}$ in Figure 3 is the difference between North per capita saving and capital erosion, and South excess demand $X D_{S}$ is the difference between its capital erosion and saving. Convexity of $X D_{S}$ follows from analysis of the host country in Figure 1 and concavity of $X S_{N}$ from symmetric conditions.

Where the two curves in Figure 3 intersect, the two capital/labor ratios, $k_{N}$ and $k_{S}$, would be equal and foreign investment is zero with equalized capital returns in the two countries. Income per capita would be higher in $N$ due to repatriated interest income $r^{s} k_{F}$.

The steady state in (7) may occur before the capital/labor ratios are equalized depending on model parameters. For simplicity assume $\theta_{N}=\theta_{S}=\theta$ with the two countries differing only in their saving rates. The steady state solution to (7) is then

$$
\begin{aligned}
& k_{N}=\left[\left(\sigma_{S} r_{S}-(\theta(1+\theta)) \sigma_{N} y_{N}+\left(\sigma_{N} r_{S}-\theta\right) \sigma_{S} y_{S}\right] / \Delta_{2}\right. \\
& k_{S}=\left[\left(\sigma_{N} r_{S}-\theta(1+\theta)\right) \sigma_{S} y_{S}+\left(\sigma_{S} r_{S}-\theta\right) \sigma_{N} y_{N}\right] / \Delta_{2} \\
& k_{F}=\theta\left(\sigma_{S} y_{S}-\sigma_{N} y_{N}\right) / \Delta_{2},
\end{aligned}
$$

where $\Delta_{2} \equiv \theta\left[\left(\sigma_{N}+\sigma_{S}\right) r_{S}-\theta(\theta+2)\right]$ and the steady state notation is omitted for simplicity. If $\Delta_{2}$ is negative, country $N$ would be the source country with positive $k_{F}$ given higher saving per capita, $\sigma_{N} y_{N}>\sigma_{S} y_{S}$. Continuing the example with $\sigma_{N}=0.2$ and adding $\sigma_{S}=0.1$, the determinant $\Delta_{2}$ is negative if $r_{S}<0.27$ or $k_{S}<1.9$. The following analysis assumes $\Delta_{2}>0$ with required parameter restrictions for a sensible economic solution with positive $k_{N}$ and $k_{S}$.

The total capital located in $S$ in the steady state from (8) is $k_{S}+k_{F}=\left[\left(\sigma_{N} r_{S}-\right.\right.$ $\left.\left.\theta^{2}\right) \sigma_{S} y_{S}+\left(\sigma_{S} r_{S}-2 \theta\right) \sigma_{N} y_{N}\right] / \Delta_{2}$, which is less than $k_{N}$ since $\theta>\theta^{2}$ and $2 \theta>\theta(1+\theta)$. The steady state in Figure 3 occurs where $k_{N}-\left(k_{S}+k_{F}\right)=\theta(1-\theta)\left(\sigma_{N} y_{N}-\sigma_{S} y_{S}\right) / \Delta_{2}>0$, implying $\sigma_{N} y_{N}>\sigma_{S} y_{S}$ and $k_{F}>0$. Foreign investment perpetually flows from capital abundant $N$ to capital scarce $S$ to maintain $k_{N}, k_{S}$, and $k_{F}$ moving just enough capital 
from frugal North to the free-spending South. There is incomplete convergence with a higher capital return in $S$ and higher wage in $N$. The imperfect foreign investment function $\varphi\left(\alpha k_{N}-k_{S}\right)$ where $\alpha<1$ would contribute to incomplete convergence and $\varphi<1$ would slow the convergence process.

An alternative assumption that saving and depreciation rates are identical but labor growth rates differ leads to the same conclusion. Foreign investment moves just enough capital from the low labor growth North to the high labor growth South to keep $k_{N}, k_{S}$, and $k_{F}$ constant.

The capital-abundant country defined in terms of home-owned capital would be the steady state source. Where $K_{F}$ represents the stock of foreign investment, steady state capital/labor ratios are $\left(K_{N}-K_{F}\right) / L_{N}$ and $\left(K_{S}+K_{F}\right) / L_{S}$ where $K_{N}$ and $K_{S}$ represent home-owned capital. Using these two capital/labor ratios, $K_{F}=\left(K_{N} L_{S}-K_{S} L_{N}\right) /$ $\left(L_{N}+L_{S}\right)$, implying $K_{N} / L_{N}>K_{S} / L_{S}$.

\section{Conclusion}

The present growth model separates foreign from domestic capital recognizing that a steady state occurs where both capital/labor ratios are stationary. Some countries would become perpetual investment hosts and others sources depending on their saving propensity, labor growth rates, and foreign investment openness. As an example, perhaps, the US with its relatively low saving and high labor growth rates could expect a perpetual trade deficit and capital account surplus with China.

The present model provides a framework to re-examine the influence of a host of issues related to successful foreign investment. Borensztein et al. (1998) and Lipsey (2000) find that foreign investment succeeds when there are higher levels of education, and Balasubramanyam et al. (1999) add size of the domestic market and the competitive environment. Bevan and Estrin (2000) and Rodrik et al. (2004) show the importance of political/legal institutions and issues, and Bengoa and Sánchez-Robles (2003) economic stability and liberalized markets. Waldkirch (2003) finds foreign investment increased in NAFTA suggesting regional integration plays a role. These influences would affect the accumulation of foreign capital in the present model. The present model of growth and foreign capital contributes to understanding the incomplete convergence noted in empirical studies such as Rassekh (2004).

\section{References}

Aitken, Brian and Ann Harrison, "Do Domestic Firms Benefit from Direct Foreign Investment?" American Economic Review 89 (1999):605-18.

Aitken, Brian, Ann Harrison, and Robert Lipsey, "Wages and Foreign Ownership: A Comparative Study of Mexico, Venezuela, and the Unites States," Journal of International Economics 40 (1996):345-71.

Balasubramanyam, V.N., M. Salisu, and D. Sapsford, "Foreign Direct Investment as an Engine of Growth," Journal of International Trade and Economic Development 8 (1999):27-40.

Barro, Robert and Xavier Sala-i-Martin, Economic Growth (chapters 3.1, 3.2, 8.3), Cambridge, MA: MIT Press (1999).

Bengoa, Marta and Blanca Sánchez-Robles, "FDI, Economic Freedom and Growth: New Evidence from Latin America," European Journal of Political Economy 19 (2003):529-45.

Berthelemey, Jean-Claude and Sylvie Demurger, "Foreign Direct Investment and Economic Growth: Theory and Application to China," Review of Development Economics 4 (2000):14055.

Bevan, A.A. and S. Estrin, "The Determinants of Foreign Direct Investment in Transition Economies," CEPR Discussion Paper No. 2638 (2000). 
Blomström, Magnus, Robert Lipsey and Mario Zejan, "What Explains Developing Country Growth?" NBER Working Paper No. 4132 (1992).

Borensztein, Eduardo, Jose De Gregorio, and Jong-Wha Lee, "How Does Foreign Direct Investment affect Economic Growth," Journal of International Economics 45 (1998):115-35.

Cass, David, "Optimum Growth in an Aggregative Model of Capital Accumulation," Review of Economic Studies 32 (1965):233-40.

De Gregorio, Jose, "Economic Growth in Latin America," Journal of Development Economics 39 (1992):59-84.

Feenstra, Robert and Tracy Lewis, “Trade Adjustment Assistance and Pareto Gains from Trade," Journal of International Economics 36 (1994):201-22.

Grossman, Gene and Carl Shapiro, “A Theory of Factor Mobility," Journal of Political Economy 90 (1982):1054-69.

Hamermesh, Daniel, "Labour Demand and the Structure of Adjustment Costs," American Economic Review 79 (1989):674-89.

Koopmans, Tjalling, "On the Concept of Optimal Economic Growth," The Econometric Approach to Development Planning, Amsterdam: North Holland (1965).

Leamer, Edward, "Welfare Computations and the Optimal Staging of Tariff Reductions in Models with Adjustment Costs," Journal of International Economics 10 (1980):21-36.

Lipsey, Robert E., "The Role of Foreign Direct Investment in International Capital Flows," NBER Working Paper No. 7094 (2000).

Lucas, Robert, "Why Doesn't Capital Flow from Rich to Poor Countries?" American Economic Review 80 (1990):92-6.

Mussa, Michael, "Imperfect Factor Mobility and the Distribution of Income," Journal of International Economics 12 (1982):124-41.

Neary, J. Peter, "Short-Run Capital Specificity and the Pure Theory of International Trade," The Economic Journal 88 (1978):488-510.

Ramsey, Frank, “A Mathematical Theory of Saving," Economic Journal 38 (1928):543-59.

Rassekh, Farhad, "The Interplay of International Trade, Economic Growth, and Income Convergence: A Brief Intellectual History of Recent Developments," Journal of International Trade and Economic Development 13 (2004):371-95.

Rodrik, Dani, Arvind Subramanian, and Francesco Trebbi, "Institutions Rule: The Primacy of Institutions over Geography and Integration in Economic Development," Journal of Economic Growth 9 (2004):131-65.

Solow, Robert, "A Contribution to the Theory of Economic Growth," Quarterly Journal of Economics 70 (1956):65-94.

Swan, Trevor, "Economic Growth and Capital Accumulation," Economic Record 32 (1956):33461.

Waldkirch, Andreas, "The 'New Regionalism' and Foreign Direct Investment: The Case of Mexico," Journal of International Trade and Economic Development 12 (2003):185-216. 